\title{
Biochemical composition, nutraceutical profile, and GC-MS analysis of novel euryhaline microalgal cultures from Punjab, India.
}

Diksha Garg ( $\sim$ diksha.garg1232@gmail.com )

Punjab Agricultural University https://orcid.org/0000-0002-5324-6878

Urmila Gupta

Punjab Agricultural University

\section{Research Article}

Keywords: Microalgae, nutraceutical, $\beta$-carotene, total phenol, phycocyanin

Posted Date: February 25th, 2022

DOI: https://doi.org/10.21203/rs.3.rs-1276946/v1

License: (c) (i) This work is licensed under a Creative Commons Attribution 4.0 International License.

Read Full License 


\title{
Biochemical composition, nutraceutical profile, and GC-MS analysis of novel euryhaline microalgal cultures from Punjab, India
}

\author{
Diksha Garg ${ }^{1 *}$ and Urmila Gupta ${ }^{1,2}$ \\ ${ }^{1}$ Department of Microbiology, Punjab Agricultural University, Ludhiana-141004 \\ ${ }^{2}$ Department of Renewable Energy Engineering, Punjab Agricultural University, Ludhiana-141004 \\ E-mail: *diksha.garg1232@gmail.com
}

\section{(a) Abstract}

Microalgae have gained recognition in the scientific community as a potential source of nutraceuticals because it is a sustainable reservoir having the capability to substitute the industrial production of ordinary organic chemical based health supplements. The biomass of microalgae incorporates various functional biomolecules like chlorophyll, carotenoids and phenols that exhibit therapeutic properties and serve as nutraceuticals. In spite of the higher production of the microalgal biomass, their biochemical composition differs, and lack of characterization for nutraceutical properties are the prime hindrance in upscaling these bio-factories. Nutraceuticals are nutrient components of the food that not only exhibit many health benefits but also prevent the occurrence of various health disorders. Two euryhaline microalgal strains BGLR8 and BGLR16, isolated from water logged areas of Punjab, India were screened for biomass production and biochemically characterized for the nutraceutical values. Results indicated that BGLR8 produced maximum amount of nutraceutical compounds such as lipid $(86 \mathrm{mg} / \mathrm{g})$, chlorophyll $(29.42 \mathrm{mg} / \mathrm{g})$, carotenoid $(28.82 \mathrm{mg} / \mathrm{g})$, phenols $(4.46 \mathrm{mg} / \mathrm{g})$, phycocyanin $(52 \mathrm{mg} / \mathrm{g})$, astaxanthin $(19.27 \mathrm{mg} / \mathrm{g})$ and $\beta$-carotene $(5.6 \mathrm{mg} / \mathrm{g})$ and anti-oxidant activity $(31.73 \%)$. The results of Gas Chromatography-Mass Spectrometry (GC-MS) revealed the presence of 8 therapeutic compounds viz. Dimethyl (E)-but-2-enedioate, Hexasilacyclododecane, Heptasilacyclotetradecane, Methyl (Z)-pentadec-8-enoate, Methyl octadec-13-enoate, Methyl hexadecanoate, Methyl octadecanoate, Methyl-octadeca-9,12-dienoate in BGLR8. Molecular identification through 18S rRNA gene sequencing confirmed BGLR8 to be a member of Coelastrella. (GenBank accession no.- MW443083.1).

(b) Keywords: Microalgae, nutraceutical, $\beta$-carotene, total phenol, phycocyanin.

\section{(c) Introduction}

Owing to the economic inequality and nutritional inadequacy, a large section of the global population is facing malnutrition that needs to be addressed via a multi-dimensional strategy through nutritional awareness, knowledge, self-efficacy, food fortification and supplementation. Novel and innovative ways to fulfill the nutritional demands have received increased attention in current times. Currently, there has been an emphasis on searching for medicinally and nutritionally novel functional foods known as nutraceuticals, which are derived from natural sources. Nutraceuticals are gaining massive popularity in the food industry as they can serve as a cost-effective nutritional source that can also provide therapeutic benefits and fulfill the global nutritional requirements. Using microalgal biomass for nutraceutical production is deemed suitable due to high yield and simultaneous elimination of the competition with food production [1].

Various microalgal pigments (like chlorophyll and carotenoids) are endowed with cardioprotective, anti-mutagenic, anticarcinogenic, anti-inflammatory and anti-oxidant properties. Chlorella, Chlamydomonas, Dunaliella, Micractinium, Oscillatoria, Spirulina and Scenedesmus 
are indeed protein-rich that comprises most of the essential amino acids needed by heterotrophs, as well as being a substantial source of chlorophyll. Chlorella vulgaris possess a lipid content of up to $50 \%$, thereby implying a valuable source of lipids. Extracts of Chlorella have exhibited the qualities that are anti-tumor and antioxidant activities. It can also regulate blood pressure and cholesterol levels, speeds tissue repair, boosts immunity and helps to prevent hypertension, malnutrition, gastric ulcers, constipation, and diabetes mellitus [1]. Spirulina is a good source of active oleic acid and other fatty acids like docosahexanoic acid (DHA), and c-linolenic acid. As a result, it produces prostaglandins, thromboxans and leukotrienes, which are involved in the control of immunological, inflammatory and coronary heart disease. Owing to its poor purine level, it is among the few palatable microorganisms that reduces the danger of uric acid build-up inside the body [2]. Spirulina sp. has also been shown to have beneficial benefits on weight reduction, hypertension, diabetes, as well as antiviral, antibacterial, anti-inflammatory, cancer-fighting, and antioxidant characteristics [3]. Because of these benefits, it is now used as nutritional supplements as tablet or powder, either alone or in combination with plant extracts, for human and livestock usage [4].

This study is the first to re-affirm that the euryhaline microalgae cultures isolated by Dar [5] can be a reliable source of carbohydrates, proteins, lipids, chlorophyll, $\beta$-carotene, astaxanthin, phycocyanin, phenols and flavonoids. Although multiple reports have emerged lately, regarding the nutraceutical potential of freshwater algal species, similar studies involving euryhaline microalgae strains are still scarce. Euryhaline cultures can adapt to diverse environmental conditions by synthesizing secondary metabolites. The goal of this study was to find out more about the nutraceutical prospect of the two euryhaline microalgae cultures, BGLR8 and BGLR16, sequestered from the flooded parts of Punjab, India, by using some innovative methodologies, providing for a comparative evaluation. This involved determining the biomass, carbohydrates, lipid, protein, chlorophyll, carotenoids, phenols, astaxanthin, phycocyanin, $\beta$-carotene and anti-oxidant activity, opening the way for future nutraceutical importance unique to each microalgal species. This work proposes a novel strategy for using the hitherto underutilised euryhaline microalgal biomass for innovative nutraceutical/functional food applications.

\section{(d) Material and methods}

\section{Microalgae production and maintenance}

The microalgal cultures BGLR8 and BGLR16 were previously sequestered from flooded parts of Punjab, India by Dar [5]. Sample collection was done from area at outskirts of Sri Muktsar Sahib, Punjab $\left(30^{\circ} 32^{\prime} 47.0^{\prime \prime} \mathrm{N} 74^{\circ} 40^{\prime} 00.0^{\prime \prime E}\right)$. The two cultures were microscopically examined for their purity (Olympus, 528293 Magnus Icon Freedom Model). The microalgal cultures BGLR8 and 
BGLR16 were enriched in Bold's basal medium [6] and BG-11 medium [7] respectively. Cultivation of microalgae was carried out in a 21 flask by adding 11 medium and 10\% inoculum. Each microalgal culture was incubated at $25 \pm 2^{\circ} \mathrm{C}$ and exposed to a light intensity of 8000 lux. After 30 days of growth, cultures were retained as stock cultures in low light conditions and maintained at room temperature. The stock cultures were maintained by sub-culturing into fresh culture broth at least bimonthly.

\section{Screening of the microalgal isolates by estimation of dry cell biomass}

The BGLR8 and BGLR16 microalgal cultures were screened for the biomass production. 11 of broth was dispensed in Erlenmeyer flasks of 21 capacity (in triplicate) and each flask was inoculated with $10 \%$ of fresh microalgal culture. The cultures were incubated for 35 days under the standard laboratory conditions $\left(25 \pm 2^{\circ} \mathrm{C}, 8000\right.$ lux, and $12: 12 \mathrm{~h}$ light: dark photoperiod). Centrifugation of the cells for 10 minutes was performed at 10,000 rpm, and the obtained biomass pellet was stored overnight in a hot air oven at $60^{\circ} \mathrm{C}$. The dried cell pellet was weighed to estimate dry cell biomass produced from each culture.

\section{Analysis of Biochemical composition}

\section{Estimation of carbohydrates}

The total carbohydrate amount of microalgae was estimated by DuBois et al [8] method. Ten ml of $70 \%$ ethanol was added in $1 \mathrm{ml}$ of microalgal culture to prepare the extract for carbohydrate estimation. Subsequently, in a boiling water bath, the mixture was heated, till ethanol evaporates. Extraction of carbohydrate was completed by reiterating the above step with $5 \mathrm{ml}$ of $80 \%$ ethanol. After mixing $0.9 \mathrm{ml}$ of distilled water to the $0.1 \mathrm{ml}$ of produced extract, the absolute volume was increased to $1 \mathrm{ml}$, and then $5 \mathrm{ml}$ of $5 \%$ phenol was added. The mixture was vortexed completely to guarantee legitimate mixing. In this way, $5 \mathrm{ml}$ of concentrated $\mathrm{H}_{2} \mathrm{SO}_{4}$ was added, followed by vortexing and cooling. A Spectrophotometer (Hitachi U-2800, Japan) was utilized to observe the absorbance of the last solution at $490 \mathrm{~nm}$.

\section{Estimation of proteins}

The protein content was determined using the Lowry et al [9] technique. To make the protein extracts, two $\mathrm{ml}$ of homogenised microalgae sample were mixed with one $\mathrm{ml}$ of $1 \mathrm{~N} \mathrm{NaOH}$. After that, the mixture was cooked for 15 minutes in a hot water bath at $100^{\circ} \mathrm{C}$ before chilling under running tap water. In a 1 percent sodium potassium tartarate solution, $0.1 \mathrm{ml}$ of the generated extract was combined with five $\mathrm{ml}$ of 0.5 percent $\mathrm{CuSO}_{4} .5 \mathrm{H}_{2} \mathrm{O} .0 .5 \mathrm{ml}$ of 1:1 Folin Ciocalteu's reagent was added after 10 minutes. The absorbance was measured using a UV-Vis Spectrophotometer (Hitachi U-2800, Japan) at $620 \mathrm{~nm}$ after the reaction mixture was kept at room temperature for 30 minutes. The protein content was determined using a standard calibration curve generated from Bovine Serum Albumin (BSA) at a concentration of $100 \mathrm{~g} / \mathrm{ml}$.

\section{Estimation of lipids}


The lipid content was estimated using Bligh and Dyer's [10] technique. Five gram of dried microalgal biomass were combined and homogenised in a solution containing 25 millilitres of methanol, 12.5 millilitres of chloroform, and 5 millilitres of water, then ultrasonicated for 40 minutes. After that, 12.5 $\mathrm{mL}$ chloroform and $12.5 \mathrm{~mL}$ sodium sulphate $(1.5 \%, \mathrm{w} / \mathrm{v})$ were added to the mixture. The resulting mixture was ultrasonicated for another 20 minutes. The extraction was carried out at room temperature $\left(25^{\circ} \mathrm{C}\right)$. The following equation was used to compute the total lipid content:

$$
\text { Total Lipid }=\frac{\text { Weight of liquid in aliquot } \times \text { Volume of chloroform layer }}{\text { Volume of aliquot }}
$$

\section{Analysis of algal pigments}

\section{Estimation of chlorophyll}

The chlorophyll composition was assessed utilizing the protocol of El-Baky et al [11]. $20 \mathrm{ml}$ of microalgal culture was centrifuged for 10 minutes at $6,000 \mathrm{rpm}$ at $25^{\circ} \mathrm{C}$. The pellet was dissolved in $20 \mathrm{ml}$ of 100 percent acetone and held overnight at $4^{\circ} \mathrm{C}$ in the dark for full chlorophyll extraction. The mixture was centrifuged at 10,000 rpm for 5 minutes. The resulting supernatant was used to calculate total chlorophyll concentration (T-Chl) using a spectrophotometer (UV-Vis spectrophotometer, Hitachi U-2800, Japan) using the following Lichtenthaler equations [12]:

$$
\text { Total chlorophyll }=7.05 \times \mathrm{A}_{661.6}+18.09 \times \mathrm{A}_{644.8}
$$

Where, $\mathrm{A}_{661.6}=$ Absorbance taken at wavelength $661.6 \mathrm{~nm}$

$\mathrm{A}_{644.8}=$ Absorbance taken at wavelength $644.8 \mathrm{~nm}$

\section{Estimation of carotenoid}

The carotenoid content was determined using El-Baky et al [11] standard procedure and standard equation as follows [12]:

$$
\begin{aligned}
\text { Chl a } & =\mathrm{A}_{661.6} \times 11.24-\mathrm{A}_{644.8} \times 2.04 \\
\mathrm{Chl} \mathrm{b} & =\mathrm{A}_{664.8} \times 20.13-\mathrm{A}_{661.6} \times 4.19 \\
\text { Total Carotenoid } & =\frac{1000 \times \mathrm{A}_{470}-1.82 \times \mathrm{Chl} \mathrm{a}-85.02 \times \mathrm{Chl} \mathrm{b}}{198}
\end{aligned}
$$

Where, $\mathrm{A}_{661.6}, \mathrm{~A}_{644.8}, \mathrm{~A}_{664.8}$ and $\mathrm{A}_{470}$ represent the optical density at wavelength 661.6, 644.8, 664.8 and $470 \mathrm{~nm}$. Chl a and $\mathrm{Chl} b$ represent Chlorophyll-A and Chlorophyll-B respectively.

\section{Estimation of flavonoids}

The flavonoids were calculated utilizing the method of Eom et al [13]. An aliquant of $0.5 \mathrm{ml}$ of microalgae culture was mixed with $0.1 \mathrm{ml}$ of $10 \%$ aluminium chloride and $0.1 \mathrm{ml}$ of $1 \mathrm{M}$ potassium acetate solution to make a final volume of $5 \mathrm{ml}$, and then $4.3 \mathrm{ml}$ of 80 percent Methanol was added. After the mixture was vortexed, the absorbance was measured at $415 \mathrm{~nm}$ with a UV-Vis Spectrophotometer (Hitachi U-2800, Japan). The observed absorbance was used to estimate flavonoid content using a standard curve for Quercetin generated with values ranging from 20-100 g/ml. 


\section{Quality determination of astaxanthin}

Dried microalgae biomass $(10 \mathrm{mg})$ was heated at $70^{\circ} \mathrm{C}$ in a test tube after being treated with $1 \mathrm{ml}$ of $4 \mathrm{M}$ hydrochloric acid. After cooling, the mixtures were re-suspended in $1 \mathrm{ml}$ of $100 \%$ acetone and centrifuged at $3500 \mathrm{rpm}$ for 6 minutes at $4^{\circ} \mathrm{C}$ [14]. A Hitachi UV-Vis Spectrophotometer U-2800 was used to measure the absorbance of the samples at $480 \mathrm{~nm}$.

\section{Estimation of phycocyanin}

The amount of phycocyanin was calculated utilizing the inorganic acid extraction method [15]. In a test tube, wet microalgae biomass $(0.5 \mathrm{gm})$ was mixed with $11.6 \mathrm{M}$ hydrochloric acid in a 1:2 (biomass:acid) ratio, then incubated at room temperature for 24 hours. A UV-Vis spectrophotometer (Hitachi U-2800, Japan) was used to detect absorbance at $620 \mathrm{~nm}$ and $652 \mathrm{~nm}$ the next day. The following equation was used to calculate the amount of phycocyanin in the microalgae samples:

$$
\mathrm{PC}=\frac{\mathrm{A}_{620}-0.474 \times A_{652}}{5.34}
$$

Where, $\mathrm{PC}=$ Concentration of Phycocyanin in $\mathrm{mg} / \mathrm{ml}$

$\mathrm{A}_{620}=$ Absorbance of the sample at $620 \mathrm{~nm}$

$\mathrm{A}_{652}=$ Absorbance of the sample at $652 \mathrm{~nm}$

\section{Estimation of $\beta$-carotene}

The content of $\beta$-carotene was measured utilizing the protocol of Herrero-Martnez et al [16]. In a centrifuge tube, dry microalgal powder $(0.5 \mathrm{gm})$ was combined with $0.05 \mathrm{gm}$ of $\mathrm{Na}_{2} \mathrm{CO}_{3}$ then, $4 \mathrm{ml}$ tetrahydrofuran was added. At room temperature, centrifugation of the mixture was done at 5000 revolutions per minute for 5 minutes. For extraction, the supernatant was combined with $3 \mathrm{ml}$ dichloromethane and $3 \mathrm{ml}$ 10\% NaCl. For 2 minutes, the test tube was vortexed adequately. Using a UV-Vis spectrophotometer, the bottom organic layer was measured for absorbance at $461 \mathrm{~nm}$ (Hitachi U-2800, Japan). The measured absorbance was used to estimate $\beta$-carotene with the help of a standard curve for $\beta$-carotene with concentrations ranging from $10-60 \mu \mathrm{g} / \mathrm{ml}$.

\section{Estimation of total phenol}

The methodology of Taga et al [17] devised for determining total phenols was used. In triplicates, 0.1 $\mathrm{ml}$ of methanolic microalgae extract was combined with $2 \mathrm{ml}$ of $2 \% \mathrm{Na}_{2} \mathrm{CO}_{3}$. After 2 minutes, $0.1 \mathrm{ml}$ of Folin Ciocalteu's reagent (50\%) was added. The mixture was adequately vortexed and incubated for 30 minutes at room temperature in the dark. A UV-Vis spectrophotometer was used to detect the absorbance at $720 \mathrm{~nm}$ (Hitachi U-2800, Japan). With the use of a reference curve for gallic acid concentrations ranging from $20-100 \mu \mathrm{g} / \mathrm{ml}$, the obtained absorbance was utilised to estimate total phenol content.

\section{Determination of anti-oxidant capacity by DPPH radical scavenging activity}


The 1,1-diphenyl-2-picrylhydrazyl (DPPH) free radical scavenging technique was used to determine the anti-oxidant activity of microalgal extracts [18]. $1 \mathrm{ml}$ of $0.1 \mathrm{mM}$ DPPH solution in methanol was combined with $3 \mathrm{ml}$ of $100 \mathrm{~g} / \mathrm{ml}$ methanolic extract. The absorbance was measured at $517 \mathrm{~nm}$ using a UV-Vis Spectrophotometer (Hitachi U-2800, Japan). To calculate DPPH free radical scavenging, use the following formula:

$$
\text { DPPH scavenging effect (\% inhibition })=\frac{A_{0}-A_{1}}{A_{0}} \times 100
$$

Where $\mathrm{A}_{0}$ represents the absorbance of the standard reaction and $\mathrm{A}_{1}$ represents the absorbance in the presence of all extract samples and the reference.

Qualitative determination of valuable compounds by Gas chromatography-mass spectrometry (GC-

\section{MS) analysis of microalgal biomass}

Microalgae culture BGLR8 and BGLR16 were analyzed by GC-MS. Polyphenolic compounds were extracted via a modified method of refluxing [19]. Methanol (80\% v/v) was used as a solvent for the extraction, which was carried out for 4 hours at $30^{\circ} \mathrm{C}$. Fifty $\mathrm{ml}$ of solvent was used to reflux one gram of microalgae dry powder. After refluxing for 2 hours, filtration was performed. The remaining sample from the filter paper was again refluxed for two hours with $50 \mathrm{ml}$ of solvent thrice. Centrifugation of the extracts was done at $6000 \mathrm{rpm}$, followed by vacuum evaporation at $45^{\circ} \mathrm{C}$. The vacuum evaporated tests were separated through a $0.45 \mu \mathrm{m}$ layer channel and disintegrated in the methanol in the ratio of 1:10 followed by collection in amber glass bottles.

Following processing, the concentrates were broken down using a Thermo Trace 1300 gas chromatograph coupled to a Thermo TSQ 800 Triple Quadrupole mass spectrometer with BP5MS section (30 m x $0.25 \mathrm{~mm} \times 0.25 \mathrm{~m}$ ). Helium gas (99.9\%) was used as the transporter gas at a constant flow rate of $1.0 \mathrm{ml} / \mathrm{min}$, with a 1.01 infusion volume. The column oven temperature was adjusted from $50^{\circ} \mathrm{C}$ to $280^{\circ} \mathrm{C}$ at a rate of $50^{\circ} \mathrm{C} / \mathrm{min}$ for 1.0 minute, then from 250 to $280^{\circ} \mathrm{C}$ at a rate of $15^{\circ} \mathrm{C} / \mathrm{min}$ for 18 minutes, with the injector temperature held at $280^{\circ} \mathrm{C}$. The findings of the GC-MS were translated using the National Institute of Standards and Technology's (NIST) database.

\section{Molecular Identification by 18SrRNA sequencing}

The culture was collected in the developmental phase for molecular identification of the putative microalgal culture BGLR8, and DNA was recovered utilizing the DNA isolation kit and PCR reagents provided by Chromous Biotech Pvt. Ltd., Bangalore, India. Amplification of 18S rRNA (1.8 kb) by Polymerase Chain Reaction (PCR) utilizing the following set of specific primers: $18 \mathrm{~S}$ forward-'5GTAGTCATATGCTTGTCTC-3' and 18S reverse- '5-GAAACCTTGTTACGACTT-3'. 100 ng of genomic DNA sample as a template, $400 \mathrm{ng}$ of each primer, $4 \mu \mathrm{l}$ of each dNTPs mixture, and $1 \mu \mathrm{l}$ of Taq DNA Polymerase (3U/L). In the Thermal Cylcer ABI 3500 Genetic Analyzer, denaturation at $96^{\circ} \mathrm{C}$ for 5 minutes, denaturation at $96^{\circ} \mathrm{C}$ for 30 seconds, hybridization at $50^{\circ} \mathrm{C}$ for 30 seconds, and polymerization at $60^{\circ} \mathrm{C}$ for 1.3 minutes were employed. The sequences after amplification were 
compared with a DNA ladder consisting of $1500 \mathrm{bp}$. The PCR results were sequenced using an ABI 3500 XL Genetic Analyzer. The data was analysed with Seq Scape-v 5.2 software. The sequences to be used in the Phylogenetic Tree Builder were aligned using the System Software aligner. A distance matrix was created using the Jukes-Cantor corrected distance model [20]. The distance matrix was generated using just alignment model sites; alignment inserts were excluded, and the minimum comparable position was 200. For comparative research and homologous sequence search, the National Centre for Biotechnology Information's (URL- http://www.ncbi.nlm.nih.gov/blast) Basic Local Alignment Search Tool (BLAST) method was used. The ribosomal 18S sequences were aligned using the ClustalW Multiple Alignment programme (URL- http://www.ebi.ac.uk/clustalw/). The neighbor-joining (NJ) strategy was employed to generate a phylogenetic tree using MEGA X 5.05 software. Bootstrap analysis with 1000 replications was used to examine the relative support for the branches formed by $\mathrm{NJ}$ analysis.

\section{Statistical Analysis}

Multiple comparisons with a t-test were conducted to examine the significance of the difference between mean values of different microalgae functional properties using SAS version 9.4 (SAS Institute, Inc., Cary, NC, USA).

\section{(e) Results and discussion:}

\section{Screening for biomass production}

The euryhaline microalgae cultures namely BGLR8 and BGLR16 were cultivated and screened for biomass production. BGLR16 produced significantly higher dry biomass $(8.3 \mathrm{~g} / \mathrm{L})(\mathrm{p}<0.001)$, followed by BGLR8 with 7.0 g/l (Figure 1(A)). Statistical tests showed significant differences in total biomass among the three microalgal strains $(\mathrm{p}<0.001)$. The highest dry biomass obtained as $0.06 \mathrm{~g} / \mathrm{L}$ in Dunaliella tertiolecta, which is lower than the biomass obtained in this study [21]. The biomass in various microalgal species varies because of the variation in the photosynthetic and carbon utilization efficiency depending upon the chemical kinetics of various light- dependent reactions, CalvinBenson-Bassham (CBB) cycle, tri-carboxylic acid (TCA) cycle, Embden-Meyerhof Parnas (EMP) pathway and the pentose phosphate (PP) pathway of different microalgal species [22].

\section{Analysis of Biochemical composition}

BGLR16 had the highest concentration of carbohydrates (191 mg/g of microalgae dry weight) followed by BGLR8 that produced $124 \mathrm{mg} / \mathrm{g}$ of microalgae dry weight (Figure 1(B)). The carbohydrate content in BGLR16 is much higher than other algae like Scenedesmus almeriensis, Chlorella sorokiniana, and Nannochloropsis gaditana, which were previously reported to have 88 , 128 , and $129 \mathrm{mg} / \mathrm{g}$ of carbohydrates, respectively [23]. These results are of great significance as complex carbohydrates like pectic-oligosaccharides, fructo-oligosacharides, xylo-oligosaccharide, and galacto-oligosaccharide that are derived from various microalgae species act as prebiotic compounds 
and promote the growth of specific gut microbes like Bifidobacteria and Lactobacillus. Fructooligosaccharide is also known to contain anti-inflammatory activity [24]. The results also indicate that BGLR16 had the highest protein content $(538 \mathrm{mg} / \mathrm{g})$ among the two strains evaluated $(\mathrm{p}<0.001)$ followed by BGLR8 $(511 \mathrm{mg} / \mathrm{g}$ ) (Figure 1(B)). The protein content in these microalgae cultures surpassed 50\% (dry weight), which conforms to the protein supplement guidelines accepted by Food Safety and Standards Authority of India (FSSAI). Furthermore, these microalgal cultures tested were rich (>2\% dry weight) in lipids (Figure 1(B)), with substantial quantities of lipids present in BGLR8 $(86 \mathrm{mg} / \mathrm{g})$. Statistical tests showed significant differences in total lipids among the two microalgal strains ( $\mathrm{p}<0.001)$. A previous study by Prabakaran and Ravindran [25] had shown that other algal species like Nostoc sp., Chlorella sp. and Tolypothrix sp. produce 13.27, 17.61, and $17.75 \mathrm{mg} / \mathrm{g}$ of lipids, respectively, which is less than the results reported in this study.

\section{Algal Pigments}

The total chlorophyll content varied from $8.23 \mathrm{mg} / \mathrm{g}$ to $29.42 \mathrm{mg} / \mathrm{g}$ for different microalgal species (Figure $1(\mathrm{C}))$. The results show that BGLR8 produced the highest chlorophyll content $(29.42 \mathrm{mg} / \mathrm{g})$ followed by BGLR16 $(8.23 \mathrm{mg} / \mathrm{g})$. The chlorophyll content significantly differed among the two microalgal strains $(\mathrm{p}<0.001)$. These results corroborate with the previously reported data indicating that C. pyrenoidosa can possess total chlorophyll upto $28 \mathrm{mg} / \mathrm{g}$ [26]. The biological activities associated with chlorophyll include anti-oxidant, anti-mutagenic activity, and induction of apoptosis in cancerous cells [27]. Epidemiological evidences indicated that increasing chlorophyll intake leads to a decrease in the risk associated with colorectal cancer [28].

The other economically sought-after pigments are carotenoids that have importance in food industries. Carotenoids content in BGLR8 was highest $(28.8 \mathrm{mg} / \mathrm{g}$ ) followed by BGLR16 (23.3 mg/g), both having $>20 \mathrm{mg} / \mathrm{g}$ carotenoid (Figure 1(D)). Carotenoids are produced in the event of excessive freeradical generation. They protect the cells from photo-damage by quenching the excited state of chlorophyll and maintain the continuation of the growth [29]. Data from the study of other algal species like Dunaliella sp. and Isochrysis sp. suggests that their carotenoid content is much less (10.8 and $6.1 \mathrm{mg} / \mathrm{g}$ carotenoids, respectively), than BGLR8 and BGLR16 [30], making the latter a suitable choice for high quantity carotenoid source. The various carotenoids obtained from microalgae have numerous therapeutic properties. Zeaxanthin has anti-tumour and anti-oxidant activity, and fucoxanthin possesses hepato-protective and anti-diabetic activity [31]. Similarly, Lutein prevents cataracts, atherosclerosis, and retinitis, while lycopene is known to show anti-ulcer activity and strengthens the immune system [31].

The flavonoid content of the two microalgal cultures differed significantly from each other. BGLR16 had the highest level of flavonoids $(9.75 \mathrm{mg} / \mathrm{g})$ as compared to BGLR8, respectively $(6.79 \mathrm{mg} / \mathrm{g})$ (Figure 1(E)). Compared to other algal species like Nannochloropsis gaditana, that has flavonoid content of $5.18 \mathrm{mg} / \mathrm{g}$ [32], BGLR16 had nearly two-fold higher levels of flavonoids. Flavonoids have 
been reported to show anti-oxidant activity and anti-microbial activity against Salmonella typhi and Bacillus subtilis [33]. The deep blue water-soluble pigment, phycocyanin synthesized by microalgae, has been used as a food additive. We found that BGLR 8 synthesized the highest amount of phycocyanin $(52 \mathrm{mg} / \mathrm{g}$ ) (Figure $1(\mathrm{~F})$ ). Other algal species like Galdieria sulphuraria have been reported to yield a nearly comparable concentration of $22 \mathrm{mg} / \mathrm{g}$ of Phycocyanin [34]. Phycocyanin is a potential nutraceutical compound for cancer treatment as it can inhibit the proliferation of cancer cells and destroy cancer cells [35]. Figure $1(\mathrm{G})$ demonstrates that at a level of $19.27 \mathrm{mg} / \mathrm{g}$ dry weight, astaxanthin content of BGLR8, found in this study nears the level of $19.8 \mathrm{mg} / \mathrm{g}$ astaxanthin achieved in Haematococcus pluvialis [36], supporting the idea that BGLR8 could be a prominent source of this pigment. Astaxanthin strengthens immune response, possesses anti-inflammatory, anti-oxidant activity, anti-tumor activity, ocular protective effect, anti-diabetic activity [31]. Another carotenoid pigment that is a treasure in the nutraceutical industry is $\beta$-carotene which is desirable for its coloring and vitaminic properties. Figure 1(H) illustrates that BGLR8 was able to accumulate $\beta$-carotene upto $5.6 \mathrm{mg} / \mathrm{g}$ on a dry basis. These results suggest that BGLR8 is rich in $\beta$-carotene than other algal species like Tetraselmis sp. CTP4 synthesizes $3.21 \mu \mathrm{g} / \mathrm{g}$ of $\beta$-carotene [37]. $\beta$-carotene has antioxidant activity, anti-inflammatory activity, anti-diabetic activity, anti-tumor activity and benefits cognitive function and atherogenesis [31].

\section{Anti-oxidant activity}

The therapeutic actions of phenols are primarily attributed to their anti-oxidant activity, ability to scavenge free radicals, redox metal ion chelation, gene expression modification, and involvement with cell signalling pathways. We found that the phenolic content of BGLR8 $(4.46 \mathrm{mg} / \mathrm{g})$ was higher than that of BGLR16 (3.62 mg/g) (Figure 1(E)). This value is also higher than the phenolic content of methanolic and ethanolic extract of Daphniphyllum neilgherrense, containing $2.12 \mathrm{mg} / \mathrm{g}$ and 1.90 $\mathrm{mg} / \mathrm{g}$ of total phenol, respectively [38]. Furthermore, we quantified the anti-oxidant activity and found that the highest anti-oxidant activity was demonstrated in BGLR8 (31.73\%) followed by BGLR16 (9.90\%) (Figure 1(I)). The excessive anti-oxidant activity of the BGLR8 is attributed to the hydroxyl functional groups on phenols that are potent hydrogen donators. The redox potential of phenolic compounds plays an important role in adsorbing free radicals and, as a result, quenching the $\mathrm{O}^{-1}$ and $\mathrm{O}^{-3}$ radicals. Apart from anti-oxidant activity, polyphenols are also involved in other functions. Methanolic extract rich in polyphenols obtained from Ecklonia stolinifera showed anti-diabetic activity as it significantly reduced the plasma glucose level in Diabetes Mellitus-induced rats. The anti-proliferative action of algae is determined by their total polyphenolic content [39].

\section{Gas chromatography-mass spectrometry (GC-MS) analysis of microalgal biomass}

The chromatographs for the methanolic extract of BGLR8 and BGLR16 had multiple peaks. The peak area and retention time for compounds detected in methanolic extract of BGLR8 and BGLR16, which are valuable as nutraceuticals, are presented in Table $1 \& 2$; Figures $2 \& 3$. The 8 volatile compounds 
identified by GC-MS of BGLR8 are Dimethyl (E)-but-2-enedioate, 2,2,4,4,6,6,8,8,10,10,12,12dodecamethyl-1,3,5,7,9,11-hexaoxa-2,4,6,8,10,12-hexasilacyclododecane, $\quad$ 2,2,4-1,3,5,7,9,11,13heptaoxa-2,4, , 4,6,6,8,8,10,10,12,12,14,14-tetradecamethyl 6,8,10,12,14-heptasilacyclotetraecdane, Methyl (Z)-pentadec-8-enoate, Methyl hexadecanoate, Methyl $(9 E, 12 E)$-octadeca-9,12-dienoate, Methyl octadec-13-enoate and Methyl octadecanoate. While, 4 volatile compounds identified from BGLR16 are 2,2,4,4,6,6,8,8,10,10,12,12,14,14-tetradecamethyl-1,3,5,7,9,11,13-heptaoxa2,4,6,8,10,12,14-heptasilacyclotetradecane, [4-[1,2-bis(trimethylsilyloxy)ethyl]-2 trimethylsilyloxyphenoxy]-trimethylsilane and Methyl 14-methylpentadecanoate, $(E, 7 R, 11 R)$ 3,7,11,15-tetramethylhexadec-2-en-1-ol.

\section{Molecular identification}

BGLR8 was found to contain the highest amount of lipids, chlorophyll, carotenoids, phenols, astaxanthin, phycocyanin, $\beta$-carotene and anti-oxidant activity than BGLR16. It was, therefore, selected for molecular identification through $18 \mathrm{~S}$ rRNA sequencing. The 18S rRNA sequence analysis of BGLR8 through the phylogenetic tree construction is shown in Figure 4. The BGLR8 isolate was identified as the member of Coelastrella. (GenBank accession no. MW443083.1).

\section{Conclusion}

Microalgae are lesser micro-organisms, as $97 \%$ of euryhaline microalgal species remain unexplored and uncharacterized. This lacuna highlights the demand for extensive research in bioprospecting, including isolation, identification, and growth optimization of native microalgal strains. This study provides evidence that the member of Coelastrella (GenBank accession no.- MW443083.1) exhibits potentially valuable biochemical profile rich in high-quality protein, lipids, carotenoids (such as phycocyanin, astaxanthin and $\beta$-carotene), and anti-oxidant pigments. Our results suggest that these microalgae are promising candidates for use as nutraceuticals. The member of Coelastrella sp. BGLR8 is favorable as a nutritional supplement due to its high lipids, chlorophyll, carotenoids, phenols, astaxanhin, phycocyanin, $\beta$-carotene and anti-oxidant activity.

Moreover, various potential bioactive components identified by GC-MS analysis showed propitious therapeutic activities. Therefore, the microalgae analyzed in this study could prove to be effective in manufacturing nutraceuticals. These miniature biofactories might give rise to the revolution in the energy, pharmaceutical and food industries in the future.

\section{(f) References}

[1] Matos J, Cardoso CL, Falé P, Afonso CM, Bandarra NM (2020) Investigation of nutraceutical potential of the microalgae Chlorella vulgaris and Arthrospira platensis. Int J Food Sci Technol. 55(1):303-12. https://doi.org/10.1111/ijfs.14278 
[2] Gkarane V, Ciulu M, Altmann B, Mörlein D (2020) Effect of alternative protein feeds on the content of selected endogenous bioactive and flavour-related compounds in chicken breast meat. Foods 9(4):392. https://doi.org/10.3390/foods9040392

[3] Camacho F, Macedo A, Malcata F (2019) Potential industrial applications and commercialization of microalgae in the functional food and feed industries: A short review. Mar drugs 17(6):312. https://doi.org/10.3390/md17060312

[4] Jin SE, Lee SJ, Park CY (2020) Mass-production and biomarker-based characterization of highvalue Spirulina powder for nutritional supplements. Food Chem. 325:126751. https://doi.org/10.1016/j.foodchem.2020.126751

[5] Dar RA (2017) Bioprospects of microalgal isolates from water logged area of Punjab for biogas production. Dissertation, Punjab Agricultural University, Ludhiana.

[6] Bischoff HW (1963) Phycological studies. IV. Some Algae from Enchanted Rock and Related Algal Species. University of Texas Publication 6318, 95.

[7] Stanier RY, Kunisawa R, Mandel M, Cohen-Bazire G (1971) Purification and properties of unicellular blue-green algae (order Chroococcales). Bacteriol Rev 35(2):171. https://doi.org/10.1128/br.35.2.171-205.1971

[8] Dubois M, Gilles KA, Hamilton JK, Rebers PT, Smith F (1956) Colorimetric method for determination of sugars and related substances. Anal chem 28(3):350-356. https://doi.org/10.1021/ac60111a017

[9] Lowry OH, Rosenbrough NJ, Farr AL, Randall RJ (1951) Protein measurement with the Folin Phenol Reagent. J Biol Chem 193:265-275. https://doi.org/10.1016/s0021-9258(19)52451-6

[10] Bligh EG, Dyer WJ (1959) A rapid method of total lipid extraction and purification. Can J Biochem Physiol 37(8). https://doi.org/10.1001/jama.1964.03070010125071

[11] El-Baky AHH, El-Baz FK, El-Baroty GS (2008) Characterization of nutraceutical compounds in blue green alga Spirulina maxima. J Med Plant Res 2(10):292-300. https://doi.org/10.5897/JMPR.9000331

[12] Lichtenthaler HK (1987) Chlorophylls and carotenoids: pigments of photosynthetic biomembranes. Methods $\quad$ Enzymol 148:350-382. https://doi.org/10.1016/00766879(87)48036-1

[13] Eom SH, Jin CW, Park HJ, Kim EH, Chung IM, Kim MJ, Cho DH (2007) Far infrared ray irradiation stimulates antioxidant activity in Vitis flexuosa THUNB. Berries Korean J Med Crop Sci 15(5):319-323. 
[14] Sarada R, Vidhyavathi R, Usha D, Ravishankar GA (2006) An efficient method for extraction of astaxanthin from green alga Haematococcus pluvialis. J Agric Food Chem 54(20):7585-7588. https://doi.org/10.1021/jf060737t

[15] Sivasankari S, Ravindran D (2014) Comparison of different extraction methods for phycocyanin extraction and yield from Spirulina platensis. Int J Curr Microbiol Appl Sci 3(8):904-909.

[16] Herrero-Martínez JM, Eeltink S, Schoenmakers PJ, Kok WT, Ramis-Ramos G (2006) Determination of major carotenoids in vegetables by capillary electrochromatography. J Sep Sci 29(5):660-665. https://doi.org/10.1002/jssc.200500427

[17] Taga MS, Miller EE, Pratt DE (1984) Chia seeds as a source of natural lipid antioxidants. J Am Oil Chem Soc 61(5):928-931. https://doi.org/10.1007/bf02542169

[18] Shen Q, Zhang B, Xu R, Wang Y, Ding X, Li P (2010) Antioxidant activity in vitro of the selenium-contained protein from the Se-enriched Bifidobacterium animalis 01. Anaerobe 16(4):380-386. https://doi.org/10.1016/j.anaerobe.2010.06.006

[19] Dhanani T, Shah S, Gajbhiye NA, Kumar S (2017) Effect of extraction methods on yield, phytochemical constituents and antioxidant activity of Withania somnifera. Arab J Chem 10:S1193-S1199. https://doi.org/10.1016/j.arabjc.2013.02.015

[20] Sumner JG, Jarvis PD, Francis AR (2017) A representation-theoretic approach to the calculation of evolutionary distance in bacteria. J Phys A Math 50(33):335601.

[21] Huang JJ, Bunjamin G, Teo ES, Ng D B, Lee YK (2016) An enclosed rotating floating photobioreactor (RFP) powered by flowing water for mass cultivation of photosynthetic microalgae. Biotechnol Biofuels 9(1):1-18. https://doi.org/10.1186/s13068-016-0633-8

[22] Sun H, Zhao W, Mao X. Li Y, Wu T, Chen F (2018) High-value biomass from microalgae production platforms: strategies and progress based on carbon metabolism and energy conversion. Biotechnol Biofuels 11:227. https://doi.org/10.1186/s13068-018-1225-6

[23] Hernandez D, Riano B, Coca M, Garcia-Gonzalez MC (2015) Saccharification of carbohydrates in microalgal biomass by physical, chemical and enzymatic pre-treatments as a previous step for bioethanol production. Chem Eng Sci 262:939-945. https://doi.org/10.1016/j.cej.2014.10.049

[24] Courtois J (2009) Oligosaccharides from land plants and algae: production and applications in therapeutics and biotechnology. Curr Opin Microbiol 12(3):261-273. https://doi.org/10.1016/j.mib.2009.04.007

[25] Prabakaran P, Ravindran AD (2011) A comparative study on effective cell disruption methods for lipid extraction from microalgae. Lett Appl Microbiol 53(2):150-154. https://doi.org/10.1111/j.1472-765X.2011.03082.x 
[26] Ferreira SV, Sant AC (2017) Impact of culture conditions on the chlorophyll content of microalgae for biotechnological applications. World J Microbiol Biotechnol 33(1):1-8. https://doi.org/10.1007/s11274-016-2181-6

[27] Hashem SM, El-Lahot A, Helal AM, Massoud MI (2021) Evaluation the phytochemicals and nutritional characteristics of some microalgae grown in Egypt as healthy food supplements. Egypt J Food Sci 49(1):173-85. https://doi.org/10.21608/ejfs.2021.66232.1100

[28] Ferruzzi MG, Blakeslee J (2007) Digestion, absorption, and cancer preventative activity of $\begin{array}{llll}\text { dietary chlorophyll } & \text { derivatives. Nutr } & \text { Res 27(1): }\end{array}$ https://doi.org/10.1016/j.nutres.2006.12.003

[29] Dharma A, Sekatresna W, Zein R, Chaidir Z, Nasir N (2017) Chlorophyll and total carotenoid contents in microalgae isolated from local industry effluent in West Sumatera, Indonesia. Pharma Chem 9(18): 9-11.

[30] Maadane A, Merghoub N, Ainane T, El Arroussi H, Benhima R, Amzazi S, Wahby I (2015) Antioxidant activity of some Moroccan marine microalgae: Pufa profiles, carotenoids and phenolic content. J Biotechnol 215:13-19. https://doi.org/10.1016/j.jbiotec.2015.06.400

[31] Torregrosa-Cresp J, Montero Z, Fuentes J L, Reig García-Galbis M, Garbayo I, Vílchez C, Martínez-Espinosa R M (2018) Exploring o the valuable carotenoids for the large-scale production by marine microorganisms. Mar Drugs 16(6):203. https://doi.org/10.3390/md16060203

[32] Haoujar I, Cacciola F, Abrini J, Mangraviti D, Giuffrida D, Oulad El Majdoub Y, Skali Senhaji N (2019) The contribution of carotenoids, phenolic compounds, and flavonoids to the antioxidative properties of marine microalgae isolated from Mediterranean Morocco. Molecules 24(22):4037. https://dx.doi.org/10.3390\%2Fmolecules24224037

[33] Baviskar JW, Khandelwal SR (2015) Extraction, Detection and Identification of Flavonoids from Microalgae: An Emerging Secondary Metabolite. Int J Curr Microbiol App Sci 2:110-17.

[34] Sloth JK, Jensen HC, Pleissner D, Eriksen NT (2017) Growth and phycocyanin synthesis in the heterotrophic microalga Galdieria sulphuraria on substrates made of food waste from restaurants and bakeries. Bioresour Technol 238:296-305. https://doi.org/10.1016/j.biortech.2017.04.043

[35] Jiang L, Wang Y, Yin Q (2017) Phycocyanin: A Potential Drug for Cancer Treatment. J Cancer 8(17):3416-3429. https://dx.doi.org/10.7150\%2Fjca.21058

[36] Dong S, Huang Y, Zhang R, Wang S, Liu Y (2014) Four different methods comparison for extraction of astaxanthin from green alga Haematococcus pluvialis. Sci World J 2014. https://doi.org/10.1155/2014/694305 
[37] Schüler LM, Santos T, Pereira H, Duarte P, Katkam NG, Florindo C, Varela JCS (2020) Improved production of lutein and $\beta$-carotene by thermal and light intensity upshifts in the marine microalga Tetraselmis sp. CTP4. Algal Res 45. https://doi.org/10.1016/j.algal.2019.101732

[38] Paulpriya K, Lincy MP, Tresina PS, Mohan VR (2015) In vitro anti-oxidant activity, total phenolic and total flavonoid contents of aerial extract of Daphniphyllum neilgherrense (Wt.) Rosenth. J Biol Innnov 4(6):257-68.

[39] Thomas NV, Kim SK (2011) Potential pharmacological applications of polyphenolic derivatives from marine brown algae. Environ Toxicol Pharmacol 32(3):325-335. https://doi.org/10.1016/j.etap.2011.09.004

[40] Burness CB, Deeks ED (2014) Dimethyl fumarate: a review of its use in patients with relapsingremitting multiple sclerosis. CNS Drugs 28(4):373-387. https://doi.org/10.1007/s40263-014$\underline{0155-5}$

[41] Wadkar SS, Shete CC, Inamdar FR, Wadkar SS, Gurav RV (2017) Phytochemical Screening and Antibacterial Activity of Cryptocoryne spiralis var. spiralis and Cryptocoryne retrospiralis (Roxb) Kunth. Med Aromat Plants 6(289):2167-0412. https://doi.org/10.4172/2167$\underline{0412.1000289}$

[42] Rani J, Giri RS (2016) Screening of bio-active compounds and anticancer activity of Punica granatum L. Sci World J 1(3):06-13.

[43] Arora S, Kumar G, Meena (2017) Screening and evaluation of bioactive components of Cenchrus ciliaris by an-MS alysis. Int Res J Pharm 8(6):69-76. https://doi.org/10.7897/2230-8407.08699

[44] Abubakar MN, Majinda RR (2016) GC-MS analysis and preliminary antimicrobial activity of Albizia adianthifolia (Schumach) and Pterocarpus angolensis (DC). Medicines 3(1):3. https://doi.org/10.3390/medicines3010003

[45] Krishnamoorthy K, Subramaniam P (2014) Phytochemical profiling of leaf, stem, and tuber parts of Solena amplexicaulis (Lam.) Gandhi using GC-MS. Int Sch Res Notices. https://doi.org/10.1155/2014/567409

[46] Mary APF, Giri RS (2018) GC-MS analysis of bioactive compounds of Achyranthes aspera. World J Pharm Res 7:1045-1056.

[47] Matinlinna JP, Lassila LV, Özcan M, Yli-Urpo A, Vallittu PK (2004) An introduction to silanes and their clinical applications in dentistry. Int J Prosthodont 17(2).

[48] Saikarthik J, Ilango S, Vijayakumar J, Vijayaraghavan R (2017) Phytochemical analysis of methanolic extract of seeds of Mucuna pruriens by gas chromatography mass spectrometry. Int J Pharm Sci Res 8(7):2916-21. doi: 10.13040/IJPSR.0975-8232 
[49] Beulah GG, Soris P T, Mohan VR (2018) GC-MS of bioactive determination compounds of Dendrophthoe falcata (LF) Ettingsh: An Epiphytic Plant. Int J Health Sci Res 8:261-269. 
Table 1 Composition and therapeutic application of different volatile compounds in BGLR8 analysed through GC-MS

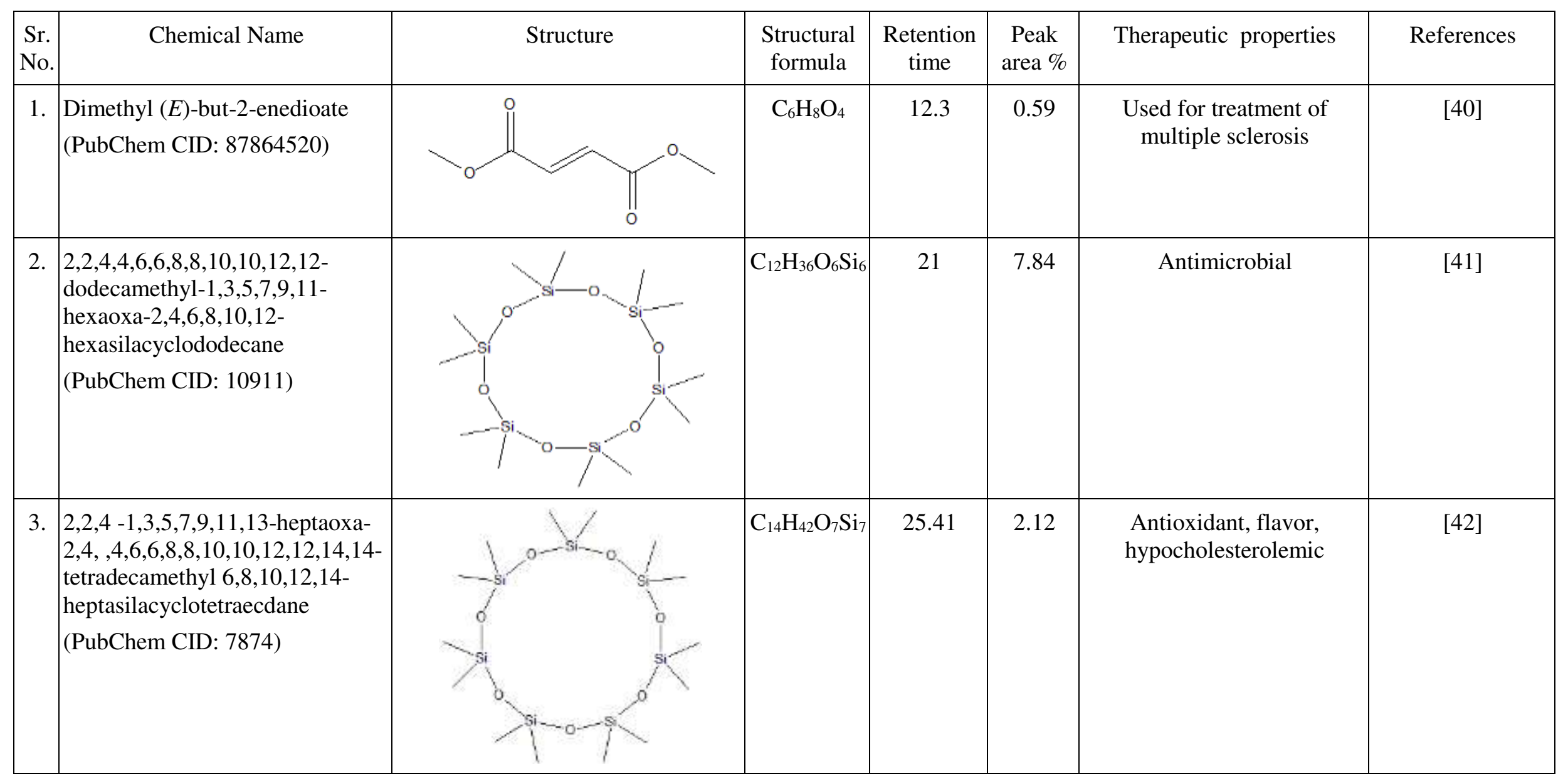




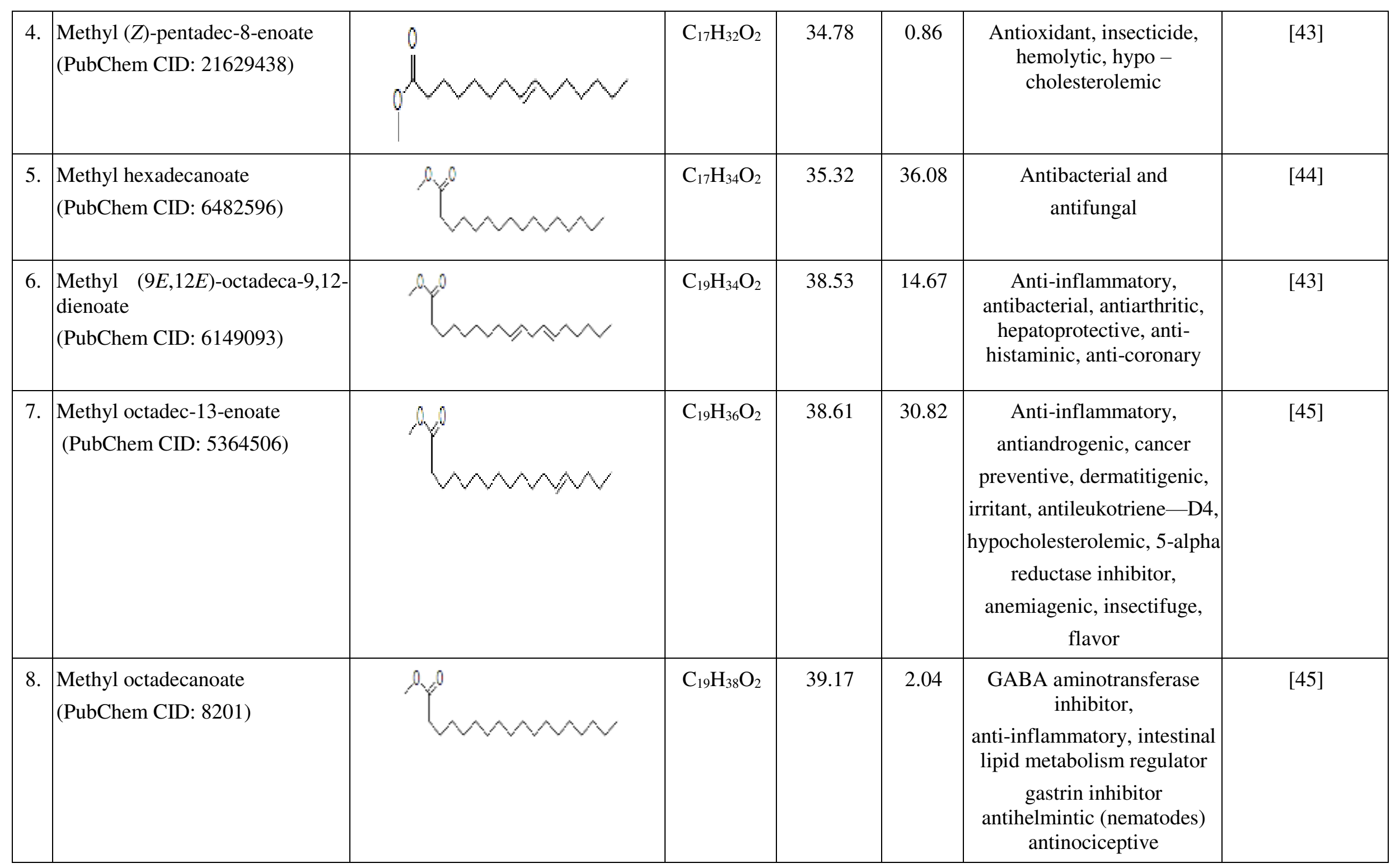


Table 2 Composition and therapeutic application of different volatile compounds in Chlorella BGLR16 analysed through GC-MS

\begin{tabular}{|c|c|c|c|c|c|c|c|}
\hline $\begin{array}{l}\text { Sr. } \\
\text { no. }\end{array}$ & Chemical Name & Structure & $\begin{array}{l}\text { Structural } \\
\text { formula }\end{array}$ & $\begin{array}{l}\text { Retention } \\
\text { time }\end{array}$ & $\begin{array}{c}\text { Peak } \\
\text { area } \\
\%\end{array}$ & $\begin{array}{l}\text { Therapeutic } \\
\text { properties }\end{array}$ & References \\
\hline 1. & $\begin{array}{l}2,2,4,4,6,6,8,8,10,10,12,12,14,14- \\
\text { tetradecamethyl-1,3,5,7,9,11,13-heptaoxa- } \\
\text { 2,4,6,8,10,12,14-heptasilacyclotetradecane } \\
\text { (PubChem CID: } 7874 \text { ) }\end{array}$ & & $\mathrm{C}_{14} \mathrm{H}_{42} \mathrm{O}_{7} \mathrm{Si}_{7}$ & 25.37 & 2.58 & $\begin{array}{l}\text { Antimicrobial, } \\
\text { antiseptic, hair } \\
\text { conditioning agent, } \\
\text { skin- conditioning } \\
\text { agent-emollient; } \\
\text { solvent }\end{array}$ & [46] \\
\hline 2. & $\begin{array}{l}\text { [4-[1,2-bis(trimethylsilyloxy)ethyl]-2- } \\
\text { trimethylsilyloxyphenoxy]-trimethylsilane } \\
\text { (PubChem CID: 530365) }\end{array}$ & & $\mathrm{C}_{20} \mathrm{H}_{42} \mathrm{O}_{4} \mathrm{Si}_{4}$ & 29.31 & 0.47 & Dentistry & [47] \\
\hline 3. & $\begin{array}{l}\text { Methyl 14-methylpentadecanoate } \\
\text { (PubChem CID: 21205) }\end{array}$ & & $\mathrm{C}_{17} \mathrm{H}_{34} \mathrm{O}_{2}$ & 35.29 & 8.68 & $\begin{array}{l}\text { Catechol-o-methyl- } \\
\text { transferase- } \\
\text { inhibitor, methyl- } \\
\text { guanidine-inhibitor }\end{array}$ & [48] \\
\hline 4. & $\begin{array}{l}(E, 7 R, 11 R)-3,7,11,15 \text {-tetramethylhexadec-2-en- } \\
\text { 1-ol } \\
\text { (PubChem CID: 145386) }\end{array}$ & & $\mathrm{C}_{20} \mathrm{H}_{40} \mathrm{O}$ & 38.84 & 4.97 & $\begin{array}{l}\text { Antimicrobial, anti- } \\
\text { inflammatory } \\
\text { anticancer, diuretic }\end{array}$ & [49] \\
\hline
\end{tabular}



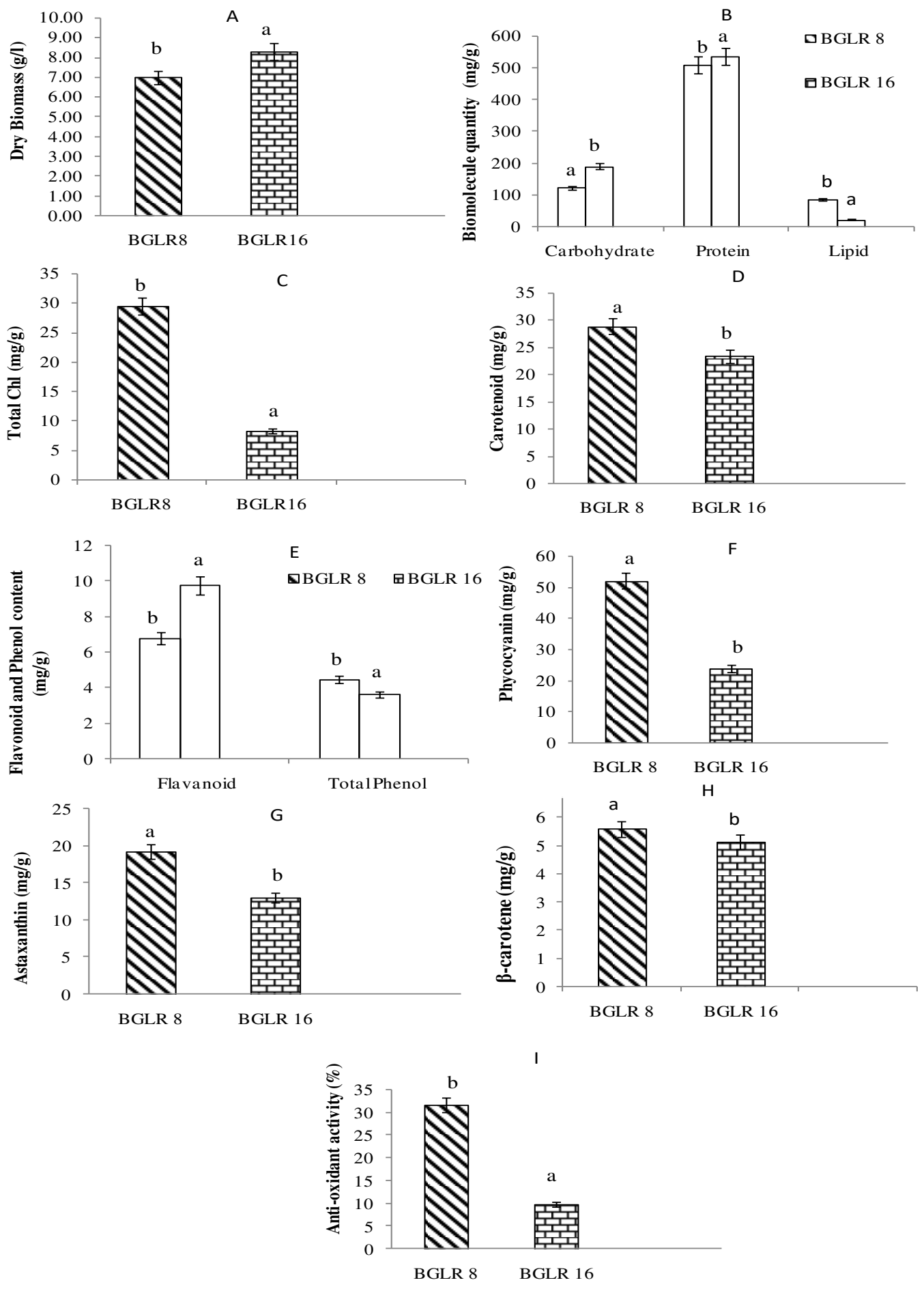

Fig. 1(a.) Dry biomass; (b.) carbohydrate, protein and lipid; (c.) total chlorophyll; (d.) total carotenoids; (e.) flavanoids and total phenols; (f.) phycocyanin; (g.) astaxanthin; (h.) $\beta$-carotene; (i.) anti-oxidant activities. The mean and standard error of the mean $(n=3)$ are used to express the data. Significant variations between samples ( $\mathrm{p}$ 0.05) are shown by different letters $(\mathrm{a}-\mathrm{b})$, whereas letters shared in common between or among samples indicate no significant differences. 


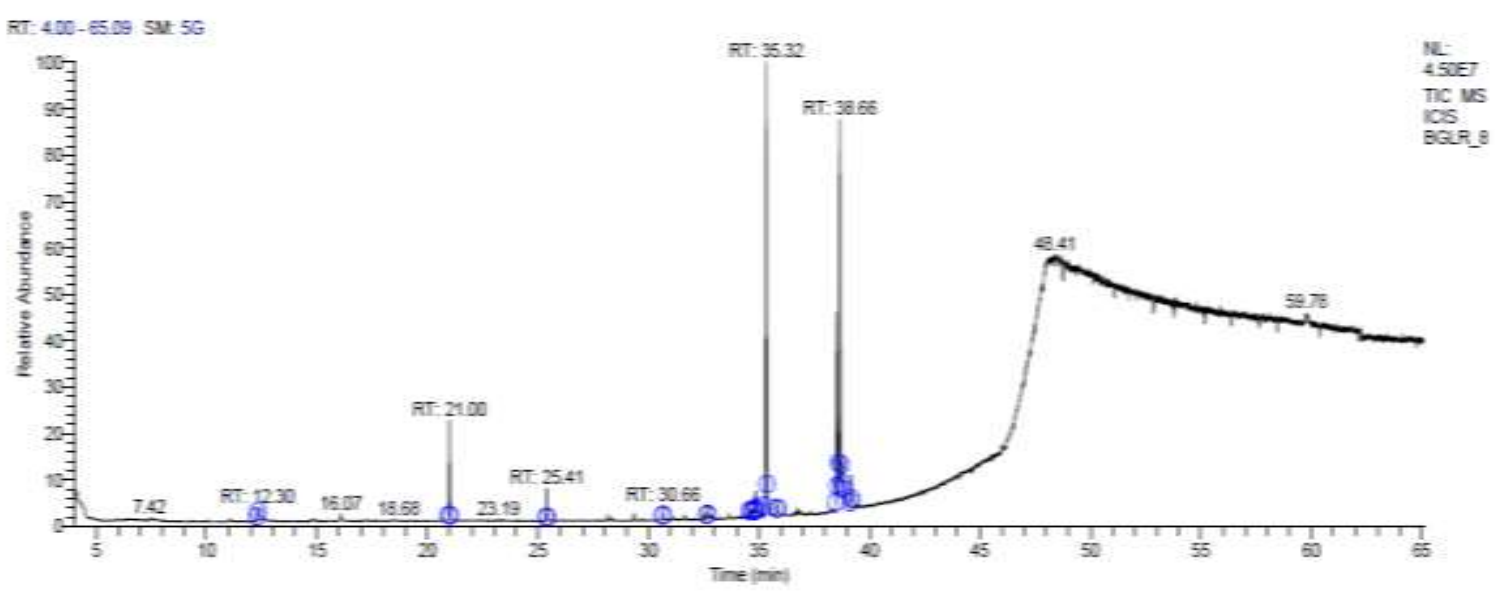

Fig. 2 Peaks for various compounds revealed in GC-MS analysis of Coelastrella sp. BGLR8.

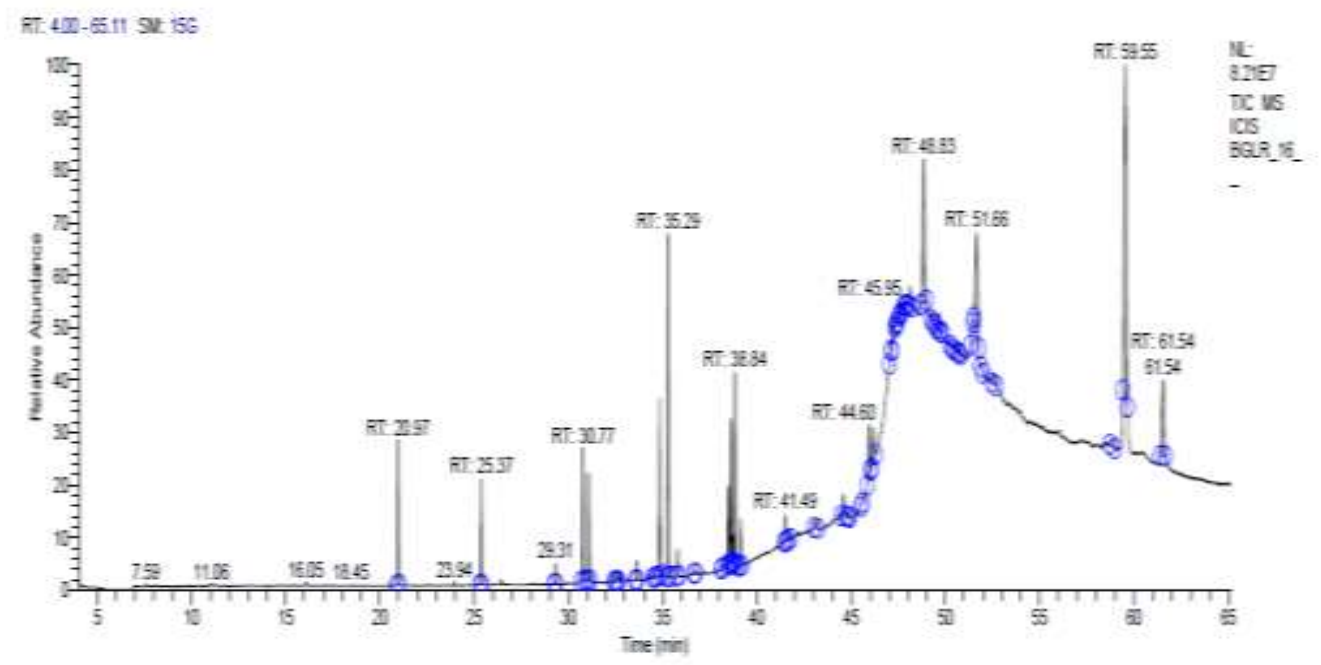

Fig. 3 Peaks for various compounds revealed in GC-MS analysis of microalgal culture BGLR16.

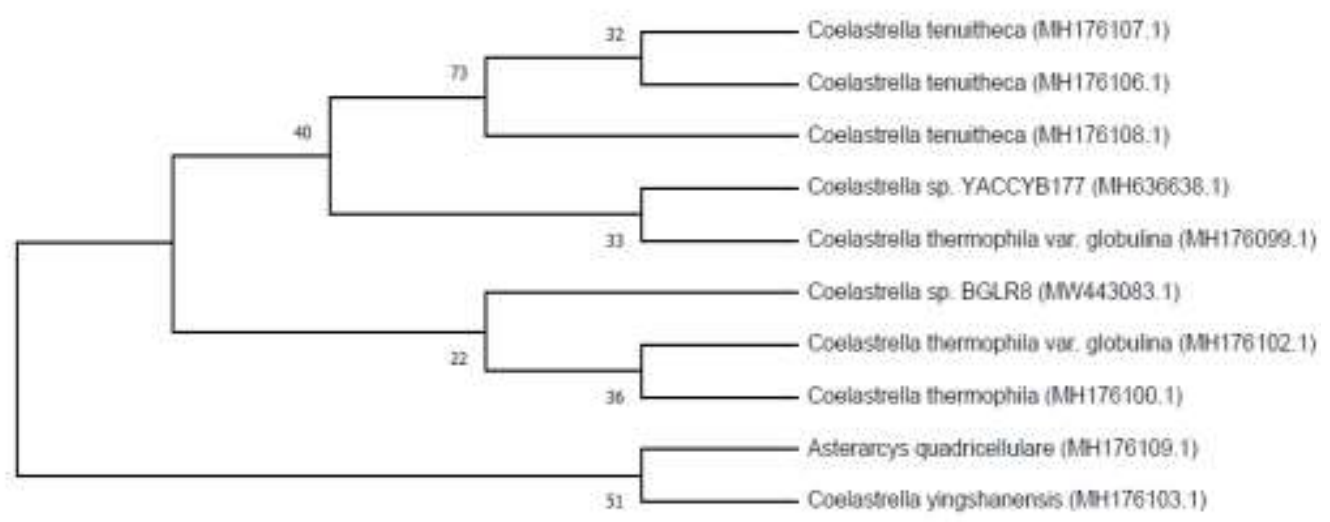

Fig. 4 The 18S rDNA sequences of BGLR8 were analysed for their phylogenetic relationships. Weighbor (a weighted form of Neighbor Joining that gives the longer distances in the distance matrix much less weight) and 100 rounds of bootstrap resampling were used to create the tree are expressed as the mean and standard error of the mean $(n=3)$. 